\title{
Molecular connectivity indices for modeling the critical micelle concentration of cationic (chloride) Gemini surfactants
}

\author{
Anna Mozrzymas ${ }^{1}$
}

Received: 26 July 2016 / Revised: 12 October 2016 / Accepted: 13 October 2016 / Published online: 17 November 2016

(C) The Author(s) 2016. This article is published with open access at Springerlink.com

\begin{abstract}
The molecular connectivity indices were used to derive the simple model relating the critical micelle concentration of cationic (chloride) gemini surfactants to their structure. One index was selected as the best to describe the effect of the structure of investigated compounds on critical micelle concentration consistent with the experimental results. This index encodes the information about molecular size, the branches, and also the information about heteroatoms. The selected model can be helpful in designing novel chloride gemini surfactants.
\end{abstract}

Keywords Chloride gemini surfactants $\cdot$ QSPR $\cdot \mathrm{Cmc} \cdot$ Molecular connectivity indices

\section{Introduction}

The quantitative structure-property relationship (QSPR) studies use the statistical models to estimate the various properties of the chemical compounds from its molecular structure [1-14]. In QSPR studies, the structure is often represented by different structural descriptors. Among the various structural parameters applied to QSPR analysis, the topological indices are often used in modeling physical, chemical, or biological properties [5-14]. The first applications of topological indices in structure-property relationship studies was proposed by Wiener in 1947 [15] and later in the 1975 by Randic[16]. The generalization of the Randic index are the

Anna Mozrzymas

anna.mozrzymas@up.wroc.pl

1 Department of Physics and Biophysics, Wrocław University of Environmental and Life Sciences, ul. Norwida 25, 50-375 Wrocław, Poland
Kier and Hall molecular connectivity indices [10]. The molecular connectivity indices contain considerable information about the structure of the molecule. Kier and Hall [10]widely described the information encoded by molecular connectivity indices especially on thetopological but also the electronic properties of the molecule.

Gemini surfactants consist of two hydrophobic tails and two hydrophilic heads connected by the spacer group. Due to the binding together of two conventional surfactant molecules by the spacer, these compounds have very good properties in aqueous solution. The cmc values of these surfactants are significantly lower than those of the corresponding monomeric counterparts.

In the previous paper [12], the QSPR study was performed to derive the model which relates the critical micelle concentration of gemini surfactants to their structure. The relationship was developed for a set of 21 cationic (bromide) gemini surfactants employing the molecular connectivity indices only. The previous model contains the second-order molecular connectivity index which, as was suggested in [12], probably encodes the information about the flexibility.

In the present study, the 4 models were derived. The relationships were developed for a set of 23 cationic (chloride) gemini surfactants also employing only the molecular connectivity indices. Just as in the previous study [12], the present models were derived for the molecules of various structures, i.e., the effect of all groups of the molecule on $\mathrm{cmc}$ value was taken into account. The structure of the investigated compounds are quite different from the previous bromides. Also, the test compounds differ in structure from previously studied compounds. The present study confirms that the onedescriptor model which best estimates the cmc values is that which contains the second-order molecular connectivity index, but the further analysis showed that the model which contains the first-order valence molecular connectivity index 
better describes the changes of $\mathrm{cmc}$ values of cationic (chloride) gemini surfactants caused by structure modification.

\section{Materials and methods}

\section{Dataset}

The data set contains only gemini surfactants with chlorides as counterions. The compounds were chosen to contain gemini surfactants with medium and long spacer length. The chemical structures of the investigated compounds along with their abbreviations are presented in Fig. 1. The data set contains 23 compounds of training set and 2test compounds. The chemical structures of the surfactants and the experimental values of cmc were taken from literature [17-21].

\section{Molecular connectivity indices}

Just as in the previous papers [11-13], the structure of the molecule is represented by Kier and Hall's molecular connectivity indices.

The $m$ th order molecular connectivity index is defined [10] by

$\mathrm{m}_{\chi_{k}}=\sum_{j=1}^{n_{m} m+1} \prod_{i=1}^{m}\left(\delta_{i}\right)_{j}^{-0.5}$

where $\delta_{i}$ is a connectivity degree, i.e., the number of nonhydrogen atoms to which the $i$ th non-hydrogen atom is
Fig. 1 Structures of investigated compounds and their abbreviations

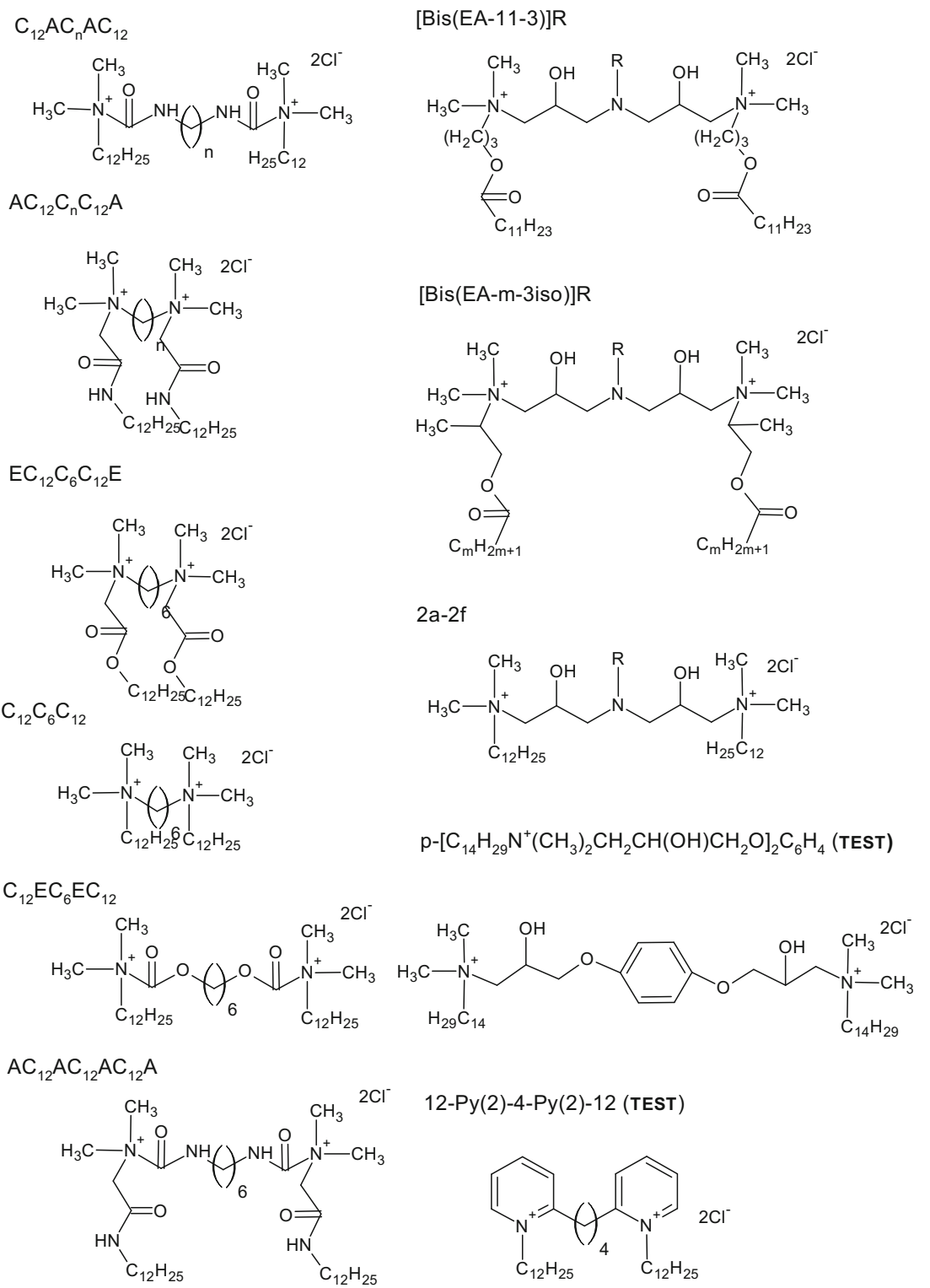


bonded; $m$ is the order of the connectivity index; $k$ denotes the type of the fragment of the molecule, for example: path (p), cluster (c), and path-cluster (pc); and $n_{m}$ is the number of fragments of type $k$ and order $m$.

For molecules with the heteroatoms, the valence connectivity degree has been defined [10] as

$\delta_{i}^{\nu}=\frac{Z_{i}^{\nu}-h_{i}}{Z_{i}-Z_{i}^{\nu}-1}$

where $Z_{i}^{\nu}$ is the number of valence electrons in the $i$ th atom, $h_{i}$ is the number of hydrogen atoms connected to the $i$ th atom, and $Z_{i}$ is the number of all electrons in the $i$ th atom.

The replacement $\delta_{i}$ by $\delta_{i}^{\nu}$ defines the valence molecular connectivity index ${ }^{\mathrm{m}} \chi_{k}^{\nu}$.

An example of calculations of molecular connectivity indices for one of the investigated gemini surfactants is presented in Appendix 1.

The molecular connectivity indices contain considerable information about the molecule. The low-order molecular connectivity indices include information about atoms and molecular size while cluster and path/cluster molecular connectivity indices include structure information about branch point and branch point environment; the valence indices add information about heteroatoms $[10,22]$. For example, ${ }^{0} \chi^{\nu}$ index includes information about heteroatoms contained in the molecule, ${ }^{1} \chi$ and ${ }^{1} \chi^{\nu}$ indices contain the information about molecular volume and molecular surface area; additionally, the ${ }^{1} \chi^{\nu}$ adds information about heteroatoms but ${ }^{3} \chi_{c}^{\nu}$ index contains the information about the number of branches and their heteroatoms [10].

\section{Statistics}

The least squares method was used to generate the formula expressing the relationship between the $\log \mathrm{cmc}$ and the molecular connectivity indices. In order to test the quality of the derived equation, three statistical parameters were used: a coefficient of determination $\left(r^{2}\right)$, a correlation coefficient $(r)$, a Fisher ratio $(F)$, and a standard deviation $(s)$. The best relationship is that which has possibly the highest values of $r^{2}, r$, and $F$ and simultaneously the lowest value of $s$.

In the case of the simple linear least-squares model, the values of statistical parameters may be calculated using the following formulas [10]:

-the coefficient of determination $: r^{2}=\frac{\sum\left(y_{i}(\mathrm{cal})-\bar{y}\right)^{2}}{\sum\left(y_{i}(\exp )-\bar{y}\right)^{2}}$

where $y_{i}(\exp )$ - the experimental value of the property, $y_{i}(\mathrm{cal})$ - the calculated value of the property and $\bar{y}=\frac{1}{n} \sum_{i=1}^{n} y_{i}$
- the correlation coefficient ( $r$ ) can be obtained from Eq. (3) as a square root of the coefficient of determination. Notice that this definition of $r$, in agreement with ref. [10], does not correspond to the standard definition of Pearson's linear correlation coefficient, although it has a similar meaning.

-the Fisher ratio : $F=(n-2) \cdot \frac{r^{2}}{\left(1-r^{2}\right)}$

-the standard deviation of the fit :

$s=\sqrt{\frac{\sum\left(y_{i}(\exp )-y_{i}(\mathrm{cal})\right)^{2}}{n-2}}$

where $n$ is the number of compounds in the data set,

-the residual for compound $i: \Delta_{i}=y_{i}(\exp )-y_{i}(\mathrm{cal})$

\section{Results and discussion}

The values of the molecular connectivity indices along with the experimental $\log \mathrm{cmc}$ values for the training set are listed in Table 1.

Basing on the data contained in Table 1, the correlation formulas containing one index were derived (Step 1). All values of statistical parameters for the relationships obtained in the first step are listed in Table 2.

As follows from Table 2, the highest values of $r$ and $F$ andthe lowest value of $s$ are for the relationship containing the second-order molecular connectivity index $\left({ }^{2} \chi\right)$. The inspection of data contained in Table 2 suggests that ${ }^{0} \chi,{ }^{1} \chi$, and ${ }^{0} \chi^{\nu}$ indices also correlate well with the logemc values. Table 3 shows the correlations between all the indices appearing in Table 1.

Two indices with $r \geq 0.97$ are highly correlated, those with $0.90 \leq r<0.97$ are appreciably correlated, the indices with $0.50 \leq r<0.89$ are weakly correlated, and those with $r<0.50$ are not correlated. As follows from the correlation matrix, there are 12pairs of highly correlated indices, among them, the pairs of ${ }^{0} \chi \mathrm{and}^{2} \chi$ indices with value of correlation coefficient 0.997 . Because of, the ${ }^{0} \chi$ and $^{2} \chi$ indices carry similar structural information related to the changes of molecular structure, i.e., the values of these indices increase with the increase of atoms and branches in the molecule [10]; therefore, we can ignore the ${ }^{0} \chi$ index in further considerations. The remaining indices which highly correlate with $\log c \mathrm{c} c$ values, namely, ${ }^{2} \chi,{ }^{1} \chi$, and ${ }^{0} \chi^{\nu}$ indices also highly correlate to each other (Table 3), but they contain somewhat different structure information; 
Table 1 Experimental $\log \mathrm{g}$ cvalues [17-19] and values of molecular connectivity indices

\begin{tabular}{|c|c|c|c|c|c|c|c|c|c|c|c|}
\hline Compound & $\log c m c^{a}$ & ${ }^{0} \chi$ & ${ }^{1} \chi$ & ${ }^{2} \chi$ & ${ }^{3} \chi_{c}$ & ${ }^{4} \chi_{p c}$ & ${ }^{0} \chi^{\nu}$ & ${ }^{1} \chi^{\nu}$ & ${ }^{2} \chi^{\nu}$ & ${ }^{3} \chi_{c}^{\nu}$ & ${ }^{4} \chi_{p c}^{\nu}$ \\
\hline bis(EA-11-3)C5 & -4.31158 & 40.342595 & 25.83567 & 21.71634 & 3.77304 & 4.01125 & 37.06539 & 22.87411 & 17.76306 & 2.693502 & 2.6531996 \\
\hline bis(EA-11-3)C6 & -4.34969 & 41.049702 & 26.33567 & 22.069896 & 3.77304 & 4.01125 & 37.772499 & 23.37411 & 18.11661 & 2.693502 & 2.6531996 \\
\hline bis(EA-11-3)C8 & -4.39041 & 42.46392 & 27.33567 & 22.777 & 3.77304 & 4.01125 & 39.18671 & 24.37411 & 18.82372 & 2.693502 & 2.6531996 \\
\hline bis(EA-9-3iso)C6 & -4.07469 & 38.54755 & 24.17711 & 20.76965 & 3.86803 & 6.47149 & 35.270345 & 21.22925 & 16.85702 & 2.77846 & 4.74458 \\
\hline bis(EA-9-3iso)C8 & -4.10568 & 39.96176 & 25.17711 & 21.47676 & 3.86803 & 6.47149 & 36.68456 & 22.22925 & 17.56413 & 2.77846 & 4.74458 \\
\hline bis(EA-11-3iso)C5 & -4.20204 & 40.66887 & 25.67711 & 21.83031 & 3.86803 & 6.47149 & 37.39167 & 22.72925 & 17.91768 & 2.77846 & 4.74458 \\
\hline bis(EA-11-3iso)C6 & -4.22841 & 41.37598 & 26.17711 & 22.18386 & 3.86803 & 6.47149 & 38.09877 & 23.22925 & 18.27124 & 2.77846 & 4.74458 \\
\hline bis(EA-11-3iso)C8 & -4.266803 & 42.79019 & 27.17711 & 22.89097 & 3.86803 & 6.47149 & 39.51299 & 24.22925 & 18.97834 & 2.77846 & 4.74458 \\
\hline $\mathrm{C}_{12} \mathrm{AC}_{2} \mathrm{AC}_{12}$ & -3.02687 & 28.53948 & 18.16987 & 14.92768 & 2.509202 & 4.85064 & 26.68149 & 16.39809 & 12.64503 & 1.80341 & 2.18671 \\
\hline $\mathrm{C}_{12} \mathrm{AC}_{6} \mathrm{AC}_{12}$ & -3.07058 & 31.367904 & 20.16987 & 16.34189 & 2.509202 & 4.85064 & 29.50991 & 18.39809 & 14.05924 & 1.80341 & 2.18671 \\
\hline $\mathrm{C}_{12} \mathrm{AC}_{12} \mathrm{AC}_{12}$ & -3.65758 & 35.61054 & 23.16987 & 18.46321 & 2.509202 & 4.85064 & 33.75255 & 21.39809 & 16.18056 & 1.80341 & 2.18671 \\
\hline $\mathrm{C}_{12} \mathrm{C}_{6} \mathrm{C}_{12}{ }^{\mathrm{b}}$ & -2.88606 & 26.79899 & 17.32843 & 14.1066 & 2.41421 & 2.41421 & 26.69342 & 16.96798 & 13.544065 & 2.15934 & 2.15934 \\
\hline $\mathrm{C}_{12} \mathrm{EC}_{6} \mathrm{EC}_{12}$ & -3.11351 & 31.367904 & 20.16987 & 16.34189 & 2.509202 & 4.85064 & 29.32641 & 18.17658 & 13.82412 & 1.78666 & 2.03045 \\
\hline $\mathrm{AC}_{12} \mathrm{C}_{6} \mathrm{C}_{12} \mathrm{~A}$ & -3.46852 & 32.78212 & 21.11612 & 17.50965 & 2.99156 & 2.88963 & 30.92413 & 19.29044 & 15.11298 & 2.30368 & 2.00972 \\
\hline $\mathrm{AC}_{12} \mathrm{C}_{12} \mathrm{C}_{12} \mathrm{~A}$ & -3.79588 & 37.02476 & 24.11612 & 19.63097 & 2.99156 & 2.88963 & 35.16677 & 22.29044 & 17.23431 & 2.30368 & 2.00972 \\
\hline $\mathrm{EC}_{12} \mathrm{C}_{6} \mathrm{C}_{12} \mathrm{E}$ & -3.49485 & 32.78212 & 21.11612 & 17.50965 & 2.99156 & 2.88963 & 30.74062 & 19.06893 & 14.85402 & 2.27719 & 1.97915 \\
\hline $\mathrm{AC}_{12} \mathrm{AC}_{6} \mathrm{AC}_{12} \mathrm{~A}$ & -3.60206 & 37.35103 & 23.95756 & 19.74494 & 3.08655 & 5.34987 & 33.74062 & 20.72055 & 15.62816 & 1.94775 & 2.09135 \\
\hline $2 \mathrm{a}\left(\mathrm{R}=\mathrm{C}_{2} \mathrm{H}_{5}\right)$ & -3.12843 & 30.82393 & 19.54797 & 16.55666 & 3.19569 & 3.25454 & 29.48265 & 18.27316 & 14.70763 & 2.57565 & 2.53284 \\
\hline $2 \mathrm{~b}\left(\mathrm{R}=\mathrm{C}_{3} \mathrm{H}_{7}\right)$ & -3.204815 & 31.53104 & 20.04797 & 16.93708 & 3.19569 & 3.19475 & 30.18976 & 18.77316 & 15.11501 & 2.57565 & 2.48653 \\
\hline $2 \mathrm{c}\left(\mathrm{R}=\mathrm{C}_{4} \mathrm{H}_{9}\right)$ & -3.25104 & 32.23815 & 20.54797 & 17.29064 & 3.19569 & 3.19475 & 30.896865 & 19.27316 & 15.46856 & 2.57565 & 2.48653 \\
\hline $2 \mathrm{~d}\left(\mathrm{R}=\mathrm{C}_{5} \mathrm{H}_{11}\right)$ & -3.40561 & 32.94525 & 21.04797 & 17.64419 & 3.19569 & 3.19475 & 31.60397 & 19.77316 & 15.82212 & 2.57565 & 2.48653 \\
\hline $2 \mathrm{e}\left(\mathrm{R}=\mathrm{C}_{6} \mathrm{H}_{13}\right)$ & -3.50169 & 33.65236 & 21.54797 & 17.997745 & 3.19569 & 3.19475 & 32.31108 & 20.27316 & 16.17567 & 2.57565 & 2.48653 \\
\hline $2 \mathrm{f}\left(\mathrm{R}=\mathrm{C}_{8} \mathrm{H}_{17}\right)$ & -3.598599 & 35.06657 & 22.54797 & 18.70485 & 3.19569 & 3.19475 & 33.72529 & 21.27316 & 16.882775 & 2.57565 & 2.48653 \\
\hline
\end{tabular}

${ }^{\mathrm{a}}$ Thecmc values were measured in pure water at $25^{\circ} \mathrm{C}$

${ }^{\mathrm{b}}$ For this compound the values of molecular connectivity indices were taken from [12]

especially, their values vary with changes in molecular structure. The first-order molecular connectivity index $\left({ }^{1} \chi\right)$ decreases with the increase of branches, but the second-order molecular connectivity index $\left({ }^{2} \chi\right)$ increases with the increase of branches, whereas the valence molecular connectivity index of zero order $\left({ }^{0} \chi^{\nu}\right)$ encodes the information about heteroatoms $[10,22]$. Thus, we keep these indices in the next considerations. These indices define models $1-3$ in the first step. To these indices, the remaining indices were added separately (step 2). The values of the correlation coefficients for this step (second step) are contained in Table 4.

Because the ${ }^{2} \chi$ index alone gives $r=0.982$, therefore the relationships with pair of indices ${ }^{1} \chi$ and $^{2} \chi(r=0.982)$ and also with the pair ${ }^{0} \chi^{\nu}$ and ${ }^{2} \chi(r=0.982)$ indices can be ignored in the further investigations. Next, from Table 4 , it follows that in the case of models 1 and 3 , the values of the correlation coefficients did not change significantly, so for those models, the step by step process was ended. In the case of model 2, the values of the correlation coefficients are higher for the rela-

Table 2 Values ofstatistical parameters for Step 1

\begin{tabular}{lrrrrrrrrrr}
\hline Index & \multicolumn{1}{l}{${ }^{0} \chi$} & \multicolumn{1}{c}{${ }^{1} \chi$} & \multicolumn{1}{c}{${ }^{2} \chi$} & ${ }^{3} \chi_{c}$ & ${ }^{4} \chi_{p c}$ & ${ }^{0} \chi^{\nu}$ & ${ }^{1} \chi^{\nu}$ & ${ }^{2} \chi^{\nu}$ & ${ }^{3} \chi_{c}^{\nu}$ & ${ }^{4} \chi_{p c}^{\nu}$ \\
\hline$r$ & 0.978 & 0.976 & 0.982 & 0.864 & 0.517 & 0.975 & 0.957 & 0.946 & 0.656 & 0.636 \\
$F$ & 465.827 & 414.171 & 563.629 & 61.856 & 7.658 & 403.639 & 231.364 & 177.729 & 15.832 & 14.268 \\
$s$ & 0.104 & 0.110 & 0.095 & 0.252 & 0.429 & 0.111 & 0.144 & 0.163 & 0.378 & 0.387 \\
\hline
\end{tabular}


Table 3 Correlation matrix

\begin{tabular}{|c|c|c|c|c|c|c|c|c|c|c|}
\hline & ${ }^{0} \chi$ & ${ }^{1} \chi$ & ${ }^{2} \chi$ & ${ }^{3} \chi_{c}$ & ${ }^{4} \chi_{p c}$ & ${ }^{0} \chi^{\nu}$ & ${ }^{1} \chi^{\nu}$ & ${ }^{2} \chi^{\nu}$ & ${ }^{3} \chi_{c}^{\nu}$ & ${ }^{4} \chi_{p c}^{\nu}$ \\
\hline${ }^{0} \chi$ & 1.000 & 0.997 & 0.997 & 0.848 & 0.590 & 0.992 & 0.974 & 0.952 & 0.607 & 0.650 \\
\hline${ }^{1} \chi$ & 0.997 & 1.000 & 0.992 & 0.816 & 0.551 & 0.993 & 0.982 & 0.952 & 0.574 & 0.598 \\
\hline${ }^{2} \chi$ & 0.997 & 0.992 & 1.000 & 0.881 & 0.568 & 0.991 & 0.970 & 0.959 & 0.658 & 0.664 \\
\hline${ }^{3} \chi_{c}$ & 0.848 & 0.816 & 0.881 & 1.000 & 0.473 & 0.846 & 0.799 & 0.860 & 0.903 & 0.767 \\
\hline${ }^{4} \chi_{p c}$ & 0.590 & 0.551 & 0.568 & 0.473 & 1.000 & 0.525 & 0.443 & 0.406 & 0.161 & 0.799 \\
\hline${ }^{0} \chi^{\nu}$ & 0.992 & 0.993 & 0.991 & 0.846 & 0.525 & 1.000 & 0.992 & 0.981 & 0.647 & 0.637 \\
\hline${ }^{1} \chi^{\nu}$ & 0.974 & 0.982 & 0.970 & 0.799 & 0.443 & 0.992 & 1.000 & 0.985 & 0.621 & 0.562 \\
\hline${ }^{2} \chi^{\nu}$ & 0.952 & 0.952 & 0.959 & 0.860 & 0.406 & 0.981 & 0.985 & 1.000 & 0.740 & 0.621 \\
\hline${ }^{3} \chi_{c}^{\nu}$ & 0.607 & 0.574 & 0.658 & 0.903 & 0.161 & 0.647 & 0.621 & 0.740 & 1.000 & 0.660 \\
\hline${ }^{4} \chi_{p c}^{\nu}$ & 0.650 & 0.598 & 0.664 & 0.767 & 0.799 & 0.637 & 0.562 & 0.621 & 0.660 & 1.000 \\
\hline
\end{tabular}

The bold values mean high correlation

tionships which contain additionally ${ }^{3} \chi_{c}$ or ${ }^{3} \chi_{c}^{\nu}$ indices. The ${ }^{3} \chi_{c}$ index encodes the information about the number of branches and their environment $[10,22]$. The ${ }^{3} \chi_{c}^{\nu}$ index adds information about heteroatoms. Thus, the relationship containing the ${ }^{3} \chi_{c}^{\nu}$ index is richer in structural information than with the ${ }^{3} \chi_{c}$ index. Furthermore, the addition others indices (step 3) did not change significantly the values of correlation coefficients therefore model 2 is now defined by the pair of indices ${ }^{1} \chi$ and ${ }^{3} \chi_{c}^{\nu}$.

The obtained formulas (models 1-3) are given below:

Model $1: \log c m c=-0.17261-0.184411 \cdot \cdot^{2} \chi$

Model $2: \log \mathrm{cmc}=0.18447-0.14866 \cdot{ }^{1} \chi-0.19248 \cdot{ }^{3} \chi_{c}^{\nu}$

Model $3: \log \mathrm{cmc}=0.44266-0.12317 \cdot^{0} \chi^{\nu}$

The statistical characteristics of the descriptors included in models 1-3 are shown in Appendix 2.

The plots of the experimental $\log \mathrm{cmc}$ versus the $\log \mathrm{cmc}$ calculated using Eqs. 7-9 are presented in Figs. 2, 3, and 4.
The comparisons of the experimental $\log \mathrm{cmc}$ with the values calculated using Eqs. 7-9 presented in Figs. 2, 3, and 4 show that models $1-3$ estimate the $\log \mathrm{cmc}$ of compounds from the training set very well, and model 2 is slightly better than model 1 and better than Model 3. The values of coefficients of determination are equal to $0.964,0.966$, and 0.951 for models 1,2 , and 3 , respectively.

The plots of residuals versus the experimental values of $\log \mathrm{cmc}$ are shown in Figs. 5, 6, and 7.

The examination of the residuals (Figs. 5, 6, and 7) shows generally good agreement between the experimental and calculated values of $\log \mathrm{cmc}$. Most of the residuals are close to zero and only one residual for model 1 is slightly larger than $2 s$.

The obtained models were used to estimate the $\log \mathrm{cmc}$ values of other compounds, different from gemini surfactants from the training set. The values of the literature $\log \mathrm{cmc}$ for test compounds are listed in Table 5.

The comparison of the experimental values of logemcof the compounds used in the test with the values estimated using Eqs. 7-9 is shown in Figs. 2, 3, and 4. The agreement between predicted and experimental $\log \mathrm{cmc}$ values

Table 4 Values of correlation coefficients for models 1-3 in step 2

\begin{tabular}{lllllllllll}
\hline Indices & ${ }^{0} \chi$ & ${ }^{1} \chi$ & ${ }^{2} \chi$ & ${ }^{3} \chi_{c}$ & ${ }^{4} \chi_{p c}$ & ${ }^{0} \chi^{\nu}$ & ${ }^{1} \chi^{\nu}$ & ${ }^{2} \chi^{\nu}$ & ${ }^{3} \chi_{c}^{\nu}$ & ${ }^{4} \chi_{p c}^{\nu}$ \\
\hline Model 1 & 0.982 & 0.982 & - & 0.982 & 0.983 & 0.982 & 0.982 & 0.982 & 0.982 \\
Model 2 & 0.978 & - & 0.982 & 0.983 & 0.976 & 0.977 & 0.976 & 0.977 & 0.983 & 0.978 \\
Model 3 & 0.979 & 0.977 & 0.982 & 0.978 & 0.975 & - & 0.978 & 0.976 & 0.976 & 0.975 \\
\hline
\end{tabular}




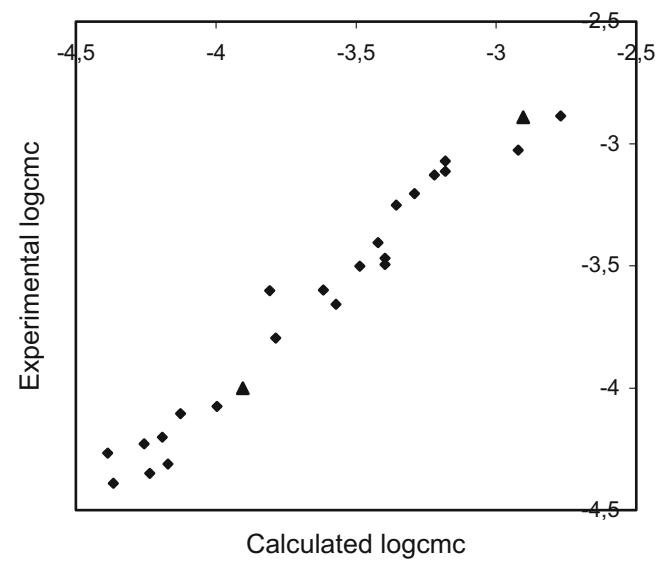

Fig. 2 Plot of the experimental logcmc versus thatcalculated using Eq. 7 for training set $(r h o m b)(r=0.982, F=563.629, s=0.095)$ and test compounds (triangle)

of the test compounds is very good. The plots of residuals (Figs. 5, 6, and 7) confirm this agreement.

In brief, the best model in the first step is that which contains the second-order molecular connectivity index $\left({ }^{2} \chi\right)$ (model 1). The second step shows that the relationship containing the first-order molecular connectivity index $\left({ }^{1} \chi\right)$ and the third-order cluster valence molecular connectivity index $\left({ }^{3} \chi_{c}^{\nu}\right)$ (model 2) estimates slightly better the values of the critical micelle concentration of cationic (chloride) gemini surfactants.

The second-order molecular connectivity index $\left({ }^{2} \chi\right)$ appearing in model 1 does not differentiate heteroatoms;it represents two-bond terms within the molecule and its values depend on the isomers of the compound [10]. The values of ${ }^{2} \chi$ index increase with the increase in length and branches of hydrocarbon

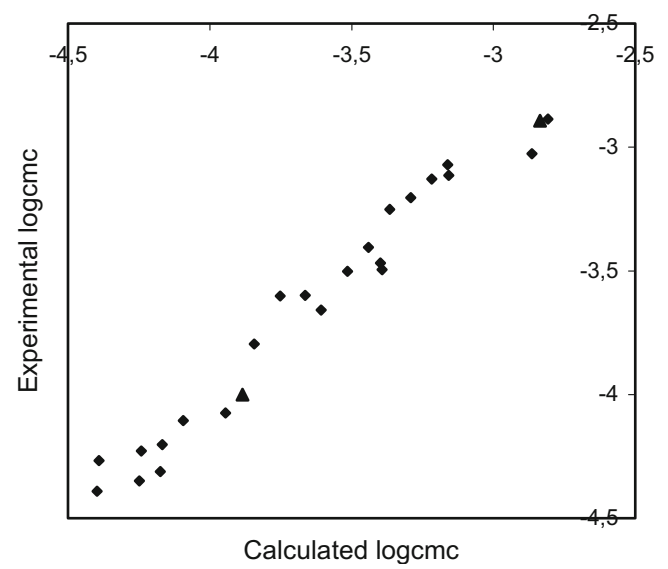

Fig. 3 Plot of the experimental logemc versus thatcalculated using Eq. 8 for training set $(r h o m b)(r=0.983, F=585.435, s=0.093)$ and test compounds (triangle)

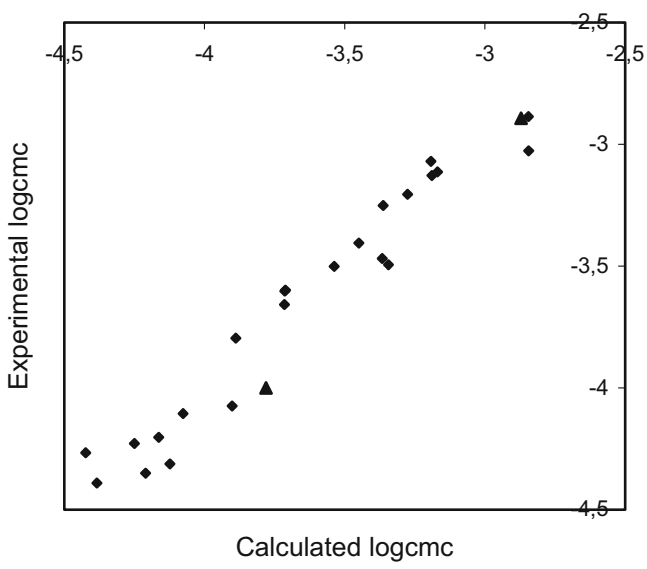

Fig. 4 Plot of the experimental logemc versus thatcalculated using Eq. 9 for training set $(r h o m b)(r=0.975, F=403.639, s=0.111)$ and test compounds (triangle)

chains. The zeroth-order valence molecular connectivity index $\left({ }^{0} \chi^{\nu}\right)$ appearing in model 3 relates to the atoms of the molecule, and it differentiates heteroatoms. The values of ${ }^{0} \chi^{\nu}$ index increase with the increase in length and branches of hydrocarbon chains, and its values are smaller for the compounds containing in their structure heteroatoms in comparison with those of their hydrocarbon analogous compounds. The first-order molecular connectivity index $\left({ }^{1} \chi\right)$ appearing in model 2 does not differentiate heteroatoms;it represents the one-bond terms within the molecule. The values of ${ }^{1} \chi$ index depend on the isomers of the compound and, in this case, decrease with the increase in branches, but its values increase with the increase in length of hydrocarbon chains. The third-order cluster valence molecular connectivity index $\left({ }^{3} \chi_{c}^{\nu}\right)$ appearing in model 2 represents

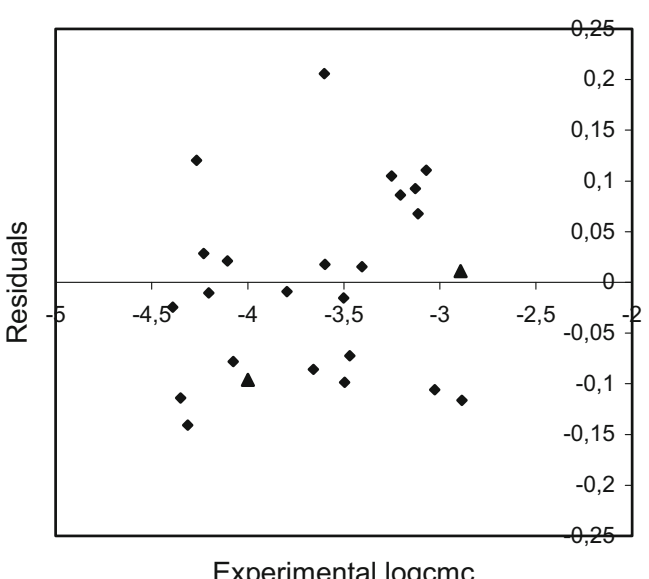

Fig. 5 Plot of residuals versus the experimental $\log \mathrm{cmc}$ values for training set (rhomb) and test compounds (triangle) (model 1) 


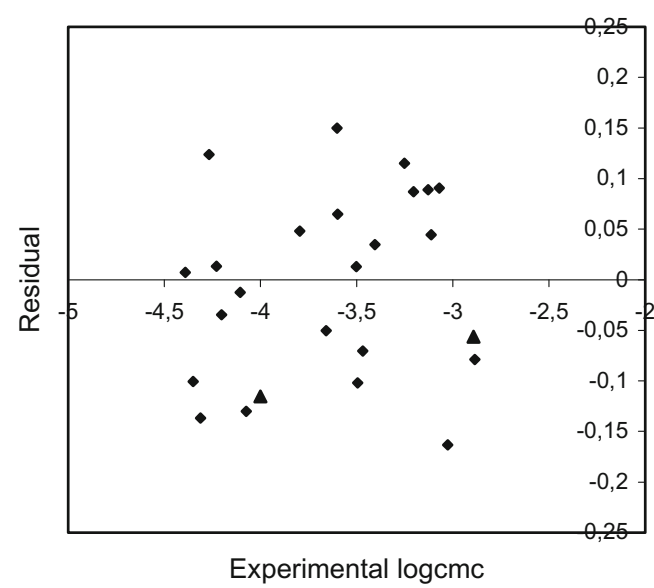

Fig. 6 Plot of residuals versus the experimental $\log \mathrm{cmc}$ values for training set (rhomb) and test compounds (triangle) (model 2)

three-bond cluster terms within the molecule, and it differentiates heteroatoms. The values of ${ }^{3} \chi_{c}^{\nu}$ index increase with the increase in branches of hydrocarbon chains, and its values are smaller for the compounds containing in their structure heteroatoms in comparison with those of their hydrocarbon analogous compounds. All models contain the molecular connectivity indices with negative coefficients, thus as their values increase, the cmc decreases.

So, from Eqs. (7-9) and also from Table 1, it follows that as the number of methylene groups increases in the hydrocarbon chains, the cmc decreases. For example, for compound bis(EA-m-3iso)C6 $(m=9,11)$, the experimental values of $\mathrm{cmc}$ are the following: 0.084 and $0.059 \mathrm{mM}[]$, and the calculated values of $\mathrm{cmc}$ are the following: 0.101 and $0.055 \mathrm{mM}$ (model 1), 0.113and $0.057 \mathrm{mM}$ (model 2), and 0.125 and $0.056 \mathrm{mM}$ (model

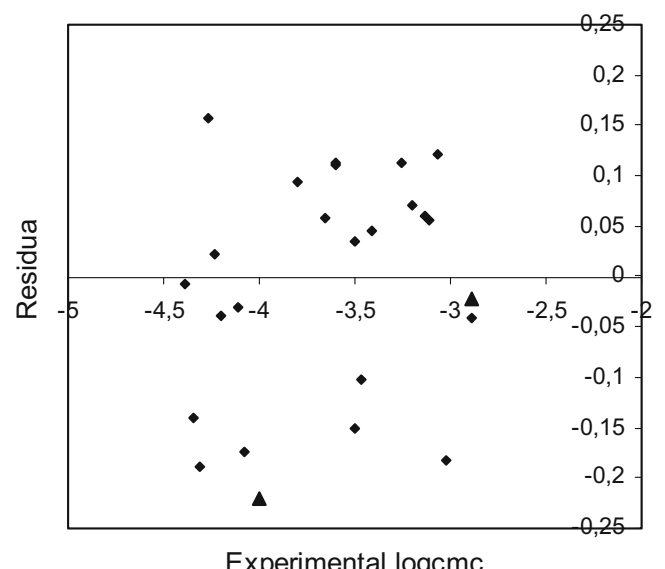

Fig. 7 Plot of residuals versus the experimental $\log \mathrm{cmc}$ values for training set (rhomb) and test compounds (triangle) (model 3)
Table 5 Experimental $\log \mathrm{cmc}$ values $[20,21]$ of test compounds

\begin{tabular}{ll} 
Compound $^{\mathrm{a}}$ & Experimentallogcmc \\
\hline $12-\mathrm{Py}(2)-4-(2) \mathrm{Py}-12 \cdot 2 \mathrm{Cl}^{-}$ & -2.89279 \\
p- $\left[\mathrm{C}_{14} \mathrm{H}_{29} \mathrm{~N}^{+}\left(\mathrm{CH}_{3}\right)_{2} \mathrm{CH}_{2} \mathrm{CH}(\mathrm{OH}) \mathrm{CH}_{2} \mathrm{O}\right]_{2} \mathrm{C}_{6} \mathrm{H}_{4} \cdot 2 \mathrm{Cl}^{-}$ & -4.0
\end{tabular}

${ }^{\mathrm{a}}$ The structures of the compounds are presented in Fig. 1

3). Also, as the number of methylene groups increases in the spacer group then the experimental and also the calculated values of the cmc decrease. For example, for compound $\mathrm{AC}_{12} \mathrm{C}_{\mathrm{n}} \mathrm{C}_{12} \mathrm{~A}(n=6,12)$, the experimental values of $\mathrm{cmc}$ are the following: 0.340 and $0.160 \mathrm{mM}[18]$, and the calculated values of $\mathrm{cmc}$ are the following: 0.401 and $0.163 \mathrm{mM}$ (model 1), 0.399and $0.143 \mathrm{mM}$ (model 2), and 0.430and $0.129 \mathrm{mM}$ (model $3)$. In the case of compounds bis(EA-m-3)R and bis(EAm-3iso)R for $R=5,6,8$, the experimental and also the calculated values of $\mathrm{cmc}$ decrease too with the increase in the alkyl chain length at the central nitrogen atom in the molecule. Thus, the increase in length of hydrocarbon chain and simultaneously in flexibility of this chain results in the decrease of $\mathrm{cmc}$ values.

The comparison of the compounds with straight and branched chains shows that the branches differently influence the calculated cmc values. For example, for compounds bis(EA-11-3)C 8 and bis(EA-11-3iso)C 8 using model 1 , we obtain the following values of $\mathrm{cmc}$ : 0.043 and 0.041 and the following using model 3: 0.041 and $0.038 \mathrm{mM}$, whereas using model 2 , we obtain 0.040 and $0.041 \mathrm{mM}$, respectively. The experimental $\mathrm{cmc}$ values are $0.041 \mathrm{mM}$ for compound bis(EA-11-3)C8 and $0.054 \mathrm{mM}$ for compound bis(EA-11-3iso)C8 [17]. It means that the experimental value of $\mathrm{cmc}$ is higher for the compound bis(EA-11-3iso)C8; therefore, the $\mathrm{cmc}$ values calculated using model 2 are in good agreement with the experimental results. Some othergemini surfactants and the corresponding calculated values of logemcare presented in Appendix 3. For the compounds presented in in Appendix 3, the cmc values which are calculated using models 1 and 2 are smaller for the compounds with branched chains than for those with straight chains and the same number of atoms. Using model 3, the cmc values are smaller only for compounds with branched carbon chains but for compounds containing heteroatoms, the branches cause the higher cmc values. The result obtained for the compounds containing heteroatoms is in agreement with the experimental one [23]. That is, for chloride compounds $\mathrm{C}_{12} \mathrm{EO}_{1} \mathrm{C}_{12}\left(0.5 \mathrm{mM}\right.$ at $\left.20{ }^{\circ} \mathrm{C}\right)$ and $\mathrm{C}_{12} \mathrm{C}_{4}(\mathrm{OH}) \mathrm{C}_{12}$ $\left(0.65 \mathrm{mM}\right.$ at $\left.20^{\circ} \mathrm{C}\right)$ [23]. 
The comparison of the heteroatom compounds with their hydrocarbon analogous compounds (Appendix 3) shows that the presence of heteroatoms in the molecules results in higher calculated, using Model 3, values of critical micelle concentration in comparison with its carbon analogous compounds. Model 2 differentiates heteroatoms only on branches but Model 1 does not differentiate heteroatoms. Some experimental results show higher values of critical micelle concentration of gemini surfactants containing in their structure heteroatoms in comparison with those of their hydrocarbon analogous compounds [18, 24-26]. That is, for example, for bromide compounds $\mathrm{C}_{12} \mathrm{EO}_{2} \mathrm{C}_{12}$ (1.09 $\left.\mathrm{mM}[24]\right)$ and $\mathrm{C}_{12} \mathrm{C}_{8} \mathrm{C}_{12}$ (0.84 mM[25]) and also for $\mathrm{C}_{12} 7 \mathrm{NHC}_{12}(1.17 \mathrm{mM}[26]$ and $1.21 \mathrm{mM}[18])$ and $\mathrm{C}_{12} \mathrm{C}_{7} \mathrm{C}_{12}(0.9 \mathrm{mM}[26])$. Also, the theoretical results obtained for cationic (bromide) gemini surfactants with various spacer group only [13] show that the presence of heteroatoms in the spacer group results in higher value of $\mathrm{cmc}$. Thus,model 3 better describes the effect of heteroatoms on cmc values.

In brief, the investigated models (models 1-3) show high correlations between $\log \mathrm{cmc}$ and the molecular connectivity indices and statistically, the best models (models1-2) can be used to estimate the values of critical micelle concentration, but the description of the effect of the structure of investigated compounds on cmc values by those models is different. All models describe the cmc values very well if we take into account only the elongation of alkyl chains. In the case of branches and heteroatoms, these models differently describe cmc values and some results differ from the experimental ones. It suggests that another index will be better to describe the effect of the structure on critical micelle concentration of cationic (chloride) gemini surfactants. Because some experimental data show that the branched chains especially branched hydrocarbon chains [17, 23, 27], and also heteroatoms [24-26], cause the higher cmc values therefore the best index which will satisfactorilydescribe the effect of the chemical structure on cmc value is the first-order valence molecular connectivity index $\left({ }^{1} \chi^{\nu}\right)$. The first-order valence molecular connectivity index $\left({ }^{1} \chi^{\nu}\right)$ is similar to the first-order molecular connectivity index $\left({ }^{1} \chi\right)$, but it includes heteroatom information. The values of ${ }^{1} \chi^{\nu}$ index increase with the increase in length of hydrocarbon chains, and its values decrease with the increase in branches. This index differentiates heteroatoms and its values are smaller than the values of the ${ }^{1} \chi$ index.

The formula containing the ${ }^{1} \chi^{\nu}$ index is the following:

Model $4: \log \mathrm{cmc}=0.56045-0.20443 \cdot{ }^{1} \chi^{\nu}$

The statistical characteristic of the selected descriptor is given in Appendix 2.
From Eq. 10, it follows that as the number of methylene groups increases in the hydrocarbon chains and also in spacer chain,the cmc decreases. For example, for compound bis(EA-m-3iso)C8 ( $m=9,11)$, the experimental values of $\mathrm{cmc}$ are the following: 0.078and $0.054 \mathrm{mM}[17]$, and the calculated values of $\mathrm{cmc}$ are the following: 0.104 and $0.040 \mathrm{mM}$. For compounds with different spacer lengths $\mathrm{AC}_{12} \mathrm{C}_{\mathrm{n}} \mathrm{C}_{12} \mathrm{~A}(n=6,12)$, the experimental values of $\mathrm{cmc}$ are the following: 0.340 and $0.160 \mathrm{mM}[18]$, and the calculated values of cmc are the following: 0.414 and $0.101 \mathrm{mM}$, respectively. The comparison of the compounds with straight and branched chains shows that the calculated values are also in good agreement with the experimental results. The example arethe compoundsbis(EA-11-3)C8 and bis(EA-11-3iso)C8, for which the experimental cmc values are the following: 0.041 and $0.054 \mathrm{mM}$, and the calculated using model $4 \mathrm{cmc}$ values are the following: 0.038 and $0.040 \mathrm{mM}$, respectively.

The plot of the experimental logemc versus the logemc calculated using Eq. 10 and the plot of residuals versus the experimental values of logemc for training set and test compounds are shown in Figs. 8 and 9

The statistical parameters show that model 4 estimates logemc values of investigated compounds lower than models 1-3, but comparison of the experimental and calculated values of cmc by means of the effect of the structural elements on cmc values shows that the values of critical micelle concentration calculated using model 4 are in good agreement with the experimental results. Some additional comparisons are presented in Appendix 3.

The data contained in Appendix 3 show that the increase in the number of atoms by lengthening or by the increase of branches causes the decrease of the $\mathrm{cmc}$ value calculated using models1-4. If we take in to account the

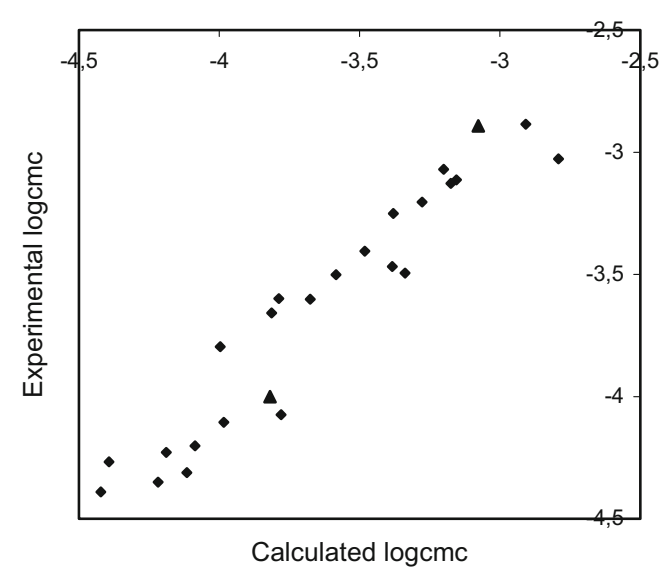

Fig. 8 Plot of the experimental logemc versus thatcalculated using Eq. 10 for training set $(r h o m b)(r=0.957, F=231.36, s=0.144)$ and test compounds (triangle) 


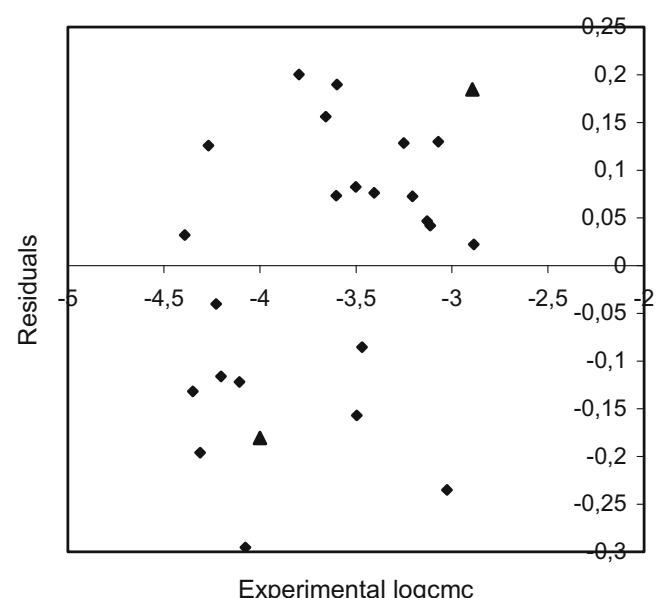

Fig. 9 Plot of residuals versus the experimental $\log \mathrm{cmc}$ values for training set (rhomb) and test compounds (triangle) (model 4)

heteroatom compounds, the effect of branches is in good agreement with experimental results obtained for bromide compounds [28]. But in the case of the elongation of hydrophilic spacer, as is for compounds $\mathrm{C}_{12} \mathrm{EO}_{\mathrm{n}} \mathrm{C}_{12}$, the experimental results [24] show the opposite behavior. Maybe it is due to the fact that the length of hydrocarbon chains has the dominant effect on $\mathrm{cmc}$ values and, in consequence, on obtained models.

The experimental studies [18] show also that the cmc values of chloride gemini surfactants are higher than of bromides ones. Indeed, the experimental $\mathrm{cmc}$ values of $\mathrm{C}_{12} \mathrm{C}_{6} \mathrm{C}_{12}$ gemini surfactant with bromides and chlorides as counterions are the following: 0.89and $1.30 \mathrm{mM}[18]$, respectively. But, using previous model [12] for bromide geminis and present (Eqs. 7-10) for chlorides ones, we obtain the following calculated values of $\mathrm{cmc}$ : $1.11 \mathrm{mM}[12]$ and $1.70 \mathrm{mM}$ (model 1), $1.56 \mathrm{mM}$ (model 2), $1.43 \mathrm{mM}$ (model 3), and $1.24 \mathrm{mM}$ (model 4), respectively. So, both the experimental and the calculated values of cmc of cationic (chloride) gemini surfactants are higher than for the bromide ones and in the case of chloride surfactants, the best estimated value is for model 4 .

It is worth to add that the test compounds (Table 5) differ in structure of spacer and head groups from the training set compounds, but also for those molecules, the agreement between predicted and experimental $\log \mathrm{cmc}$ values is very good.

\section{Conclusion}

In the present work, the cationic (chloride) gemini surfactants with various structures were taken into account. All the models obtained confirm the experimental results that the length of alkyl chains plays the major role in micelle formation. The present study shows that although the second-order molecular connectivity index correlates high with $\log \mathrm{cmc}$ values of cationic gemini surfactants, the statistically lower correlation $\log \mathrm{cmc}$ with the first order valence molecular connectivity index better describes the effect of the branches and heteroatoms on the critical micelle concentration of cationic (chloride) gemini surfactants. Becausemodel 4 (Eq. (10)) has good prediction ability of investigated compounds,it can be used to predict the critical micelle concentration and in particular to design new cationic (chloride) gemini surfactants more active in micelle formation.

Acknowledgment The statistical calculations were performed using the program Statistica 12 provided by the Wrocław University of Environmental and Life Sciences.

\section{Compliance with ethical standards}

Funding There is no financial support from any third party.

Conflict of interest The authors declare that they have no conflict of interest.

\section{Appendix 1}

To illustrate the calculation of the molecular connectivity indices, the 2agemini surfactant (Table 1) was taken into account. The first step of calculations is to draw the structural formula of the molecule and to count the values of connectivity degrees [10]. The hydrogen atoms are suppressed in graphic structural formula. The structure along with the values of connectivity and valence connectivity degrees are shown in Fig. 10.

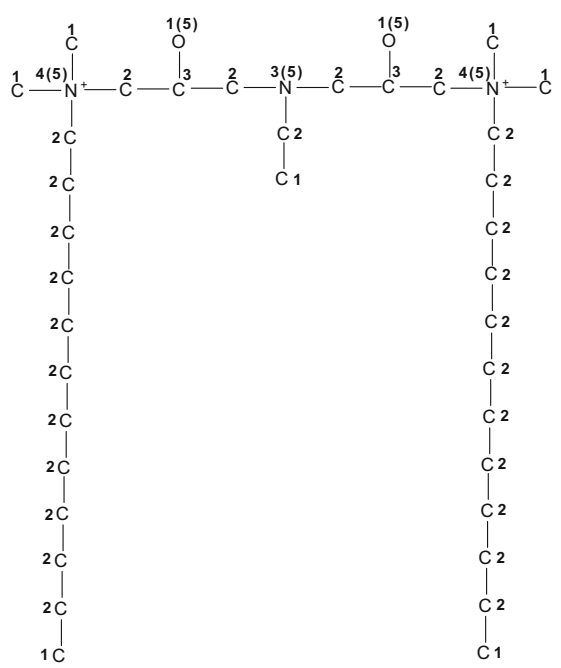

Fig. 10 Hydrogen-suppressed graphic structural formula of exemplary gemini surfactant anddelta values 
Next, the molecule is dissected into the appropriate fragments, for example: path, cluster, or path-cluster. The values of connectivity indices can be easily calculate using Eq. 1 .
The calculations of molecular connectivity indices for exemplary gemini surfactant read:

$$
\begin{aligned}
& { }^{0} \chi=\sum\left(\delta_{i}\right)^{-0.5}= \\
& =9 \cdot(1)^{-0.5}+27 \cdot(2)^{-0.5}+2 \cdot(4)^{-0.5}+3 \cdot(3)^{-0.5}= \\
& =30.82393 \\
& { }^{1} \chi=\sum\left(\delta_{i} \times \delta_{j}\right)^{-0.5}= \\
& =3 \cdot(2 \times 1)^{-0.5}+20 \cdot(2 \times 2)^{-0.5}+4 \cdot(4 \times 1)^{-0.5}+4 \cdot(2 \times 4)^{-0.5}+7 \cdot(2 \times 3)^{-0.5}+2 \cdot(3 \times 1)^{-0.5}= \\
& =19.54797 \\
& { }^{2} \chi=\sum\left(\delta_{i} \times \delta_{j} \times \delta_{k}\right)^{-0.5}= \\
& =2 \cdot(2 \times 2 \times 1)^{-0.5}+18 \cdot(2 \times 2 \times 2)^{-0.5}+4 \cdot(2 \times 2 \times 4)^{-0.5}+8 \cdot(4 \times 2 \times 1)^{-0.5}+2 \cdot(1 \times 4 \times 1)^{-0.5}+ \\
& +2 \cdot(4 \times 2 \times 3)^{-0.5}+5 \cdot(2 \times 3 \times 1)^{-0.5}+5 \cdot(2 \times 3 \times 2)^{-0.5}+2 \cdot(3 \times 2 \times 3)^{-0.5}= \\
& =16.55666 \\
& { }^{3} \chi_{c}=\sum\left(\delta_{i} \times \delta_{j} \times \delta_{k} \times \delta_{l}\right)^{-0.5}= \\
& =4 \cdot(4 \times 2 \times 2 \times 1)^{-0.5}+4 \cdot(4 \times 2 \times 1 \times 1)^{-0.5}+2 \cdot(2 \times 3 \times 2 \times 1)^{-0.5}+(2 \times 3 \times 2 \times 2)^{-0.5}= \\
& =3.19569 \\
& { }^{4} \chi_{p c}=\sum\left(\delta_{i} \times \delta_{j} \times \delta_{k} \times \delta_{l} \times \delta_{m}\right)^{-0.5}= \\
& =2 \cdot(1 \times 4 \times 2 \times 2 \times 1)^{-0.5}+4 \cdot(1 \times 4 \times 2 \times 2 \times 2)^{-0.5}+2 \cdot(1 \times 4 \times 1 \times 2 \times 3)^{-0.5}+6 \cdot(1 \times 4 \times 2 \times 2 \times 3)^{-0.5}+ \\
& +2 \cdot(1 \times 3 \times 2 \times 2 \times 3)^{-0.5}+2 \cdot(2 \times 3 \times 2 \times 2 \times 3)^{-0.5}+(2 \times 3 \times 2 \times 2 \times 1)^{-0.5}= \\
& =3.25454
\end{aligned}
$$

and

$$
\begin{aligned}
& { }^{0} \chi^{\nu}=\sum\left(\delta_{i}^{\nu}\right)^{-0.5}= \\
& =7 \cdot(1)^{-0.5}+27 \cdot(2)^{-0.5}+2 \cdot(3)^{-0.5}+5 \cdot(5)^{-0.5}= \\
& =29.48265 \\
& { }^{1} \chi^{\nu}=\sum\left(\delta_{i}^{\nu} \times \delta_{j}^{\nu}\right)^{-0.5}= \\
& =3 \cdot(2 \times 1)^{-0.5}+20 \cdot(2 \times 2)^{-0.5}+7 \cdot(2 \times 5)^{-0.5}+4 \cdot(5 \times 1)^{-0.5}+4 \cdot(2 \times 3)^{-0.5}+2 \cdot(5 \times 3)^{-0.5}= \\
& =18.27316 \\
& { }^{2} \chi^{\nu}=\sum\left(\delta_{i}^{\nu} \times \delta_{j}^{\nu} \times \delta_{k}^{\nu}\right)^{-0.5}=2 \cdot(2 \times 2 \times 1)^{-0.5}+18 \cdot(2 \times 2 \times 2)^{-0.5}+7 \cdot(2 \times 2 \times 5)^{-0.5}+2 \cdot(1 \times 5 \times 1)^{-0.5}+ \\
& +9 \cdot(1 \times 5 \times 2)^{-0.5}+8 \cdot(5 \times 2 \times 3)^{-0.5}+2 \cdot(2 \times 2 \times 3)^{-0.5}= \\
& =14.70763 \\
& { }^{3} \chi_{c}^{\nu}=\sum\left(\delta_{i}^{\nu} \times \delta_{j}^{\nu} \times \delta_{k}^{\nu} \times \delta_{l}^{\nu}\right)^{-0.5}= \\
& =4 \cdot(5 \times 2 \times 2 \times 1)^{-0.5}+4 \cdot(5 \times 2 \times 1 \times 1)^{-0.5}+2 \cdot(5 \times 2 \times 2 \times 3)^{-0.5}+(5 \times 2 \times 2 \times 2)^{-0.5}= \\
& =2.57565 \\
& { }^{4} \chi_{p c}^{\nu}=\sum\left(\delta_{i}^{\nu} \times \delta_{j}^{\nu} \times \delta_{k}^{\nu} \times \delta_{l}^{\nu} \times \delta_{k}^{\nu}\right)^{-0.5}= \\
& =2 \cdot(1 \times 5 \times 2 \times 2 \times 1)^{-0.5}+5 \cdot(1 \times 5 \times 2 \times 2 \times 2)^{-0.5}+2 \cdot(1 \times 5 \times 2 \times 3 \times 1)^{-0.5}+4 \cdot(1 \times 5 \times 2 \times 2 \times 3)^{-0.5}+ \\
& +4 \cdot(3 \times 5 \times 2 \times 2 \times 5)^{-0.5}+2 \cdot(2 \times 5 \times 2 \times 2 \times 3)^{-0.5}= \\
& =2.53284
\end{aligned}
$$




\section{Appendix 2}

The statistical characteristics of the descriptors contained in models1-4 are given in Table 6 .

Table 6 Characteristics of descriptors

\begin{tabular}{|c|c|c|c|c|c|}
\hline Model & Constant/descriptor & Coefficient & Standard error & $t$ value & $p$ value \\
\hline 1 & $\begin{array}{l}\text { Constant } \\
{ }^{2} \chi\end{array}$ & $\begin{array}{l}-0.17261 \\
-0.18411\end{array}$ & $\begin{array}{l}0.14814 \\
0.00775\end{array}$ & $\begin{array}{l}-1.165 \\
-23.741\end{array}$ & $\begin{array}{l}0.257006 \\
0.000000\end{array}$ \\
\hline 2 & $\begin{array}{l}\text { Constant } \\
{ }^{1} \chi \\
{ }^{3} \chi_{c}^{\nu}\end{array}$ & $\begin{array}{l}0.18447 \\
-0.14866 \\
-0.19248\end{array}$ & $\begin{array}{l}0.16798 \\
0.00845 \\
0.06861\end{array}$ & $\begin{array}{l}1.0982 \\
-17.587 \\
-2.806\end{array}$ & $\begin{array}{l}0.285164 \\
0.000000 \\
0.010922\end{array}$ \\
\hline 3 & $\begin{array}{l}\text { Constant } \\
{ }^{0} \chi^{\nu}\end{array}$ & $\begin{array}{l}0.44266 \\
-0.12317\end{array}$ & $\begin{array}{l}0.20543 \\
0.00613\end{array}$ & $\begin{array}{l}2.155 \\
-20.091\end{array}$ & $\begin{array}{l}0.042935 \\
0.000000\end{array}$ \\
\hline 4 & $\begin{array}{l}\text { Constant } \\
{ }^{1} \chi^{\nu}\end{array}$ & $\begin{array}{l}0.56045 \\
-0.20443\end{array}$ & $\begin{array}{l}0.27897 \\
0.01344\end{array}$ & $\begin{array}{l}2.009 \\
-15.211\end{array}$ & $\begin{array}{l}0.057569 \\
0.000000\end{array}$ \\
\hline
\end{tabular}

High absolute Student $t$ values of the descriptors express that the regression coefficients of the descriptors are significantly larger than the standard error. Descriptors with $p$ values below 0.05 (95\% confidence) are considered statistically significant [4].

As follows from Table 6, all the descriptors are statistically significant.

\section{Appendix 3}

The hydrogen-suppressed graphic structural formulas of some gemini surfactants, and the corresponding calculated, using Eqs. $7-10, \log \mathrm{cmc}$ values are contained in Table 7. 
Table 7 Hydrogen-suppressed structural formulas of some gemini surfactants and calculated logcme values

\begin{tabular}{|c|c|c|c|c|c|}
\hline & Compound & Model 1 & Model 2 & Model 3 & Model 4 \\
\hline 1 & $\underset{C_{12}}{\mathrm{C}-\mathrm{N}^{+}-\mathrm{C}-\mathrm{C}-\mathrm{C}-\mathrm{C}-\mathrm{C}-\mathrm{C}-\mathrm{N}_{\mathrm{C}_{12}^{+}}-\mathrm{C}}$ & -2.770 & -2.807 & -2.845 & -2.908 \\
\hline 2 & $\mathrm{C}-\left.\underset{\mathrm{C}_{12}}{\mathrm{~N}^{+}-\mathrm{C}-\mathrm{C}-\mathrm{C}-\mathrm{C}-\mathrm{C}-\mathrm{C}-\mathrm{C}-\mathrm{N}^{+}-\mathrm{C}}\right|_{\mathrm{C}_{12}} \mathrm{C}$ & -2.835 & -2.881 & -2.932 & -3.011 \\
\hline 3 & 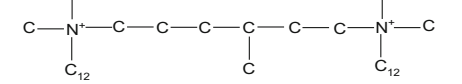 & -2.884 & -2.921 & -2.952 & -2.989 \\
\hline $4^{*}$ & $\left.\right|_{C_{12}} ^{C}-N_{N^{+}}-C-C-O-C-C-\left.\right|_{C_{12}^{+}} ^{N^{+}-C}$ & -2.705 & -2.733 & -2.721 & -2.720 \\
\hline 5 & 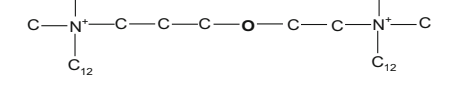 & -2.770 & -2.807 & -2.808 & -2.822 \\
\hline 6 & 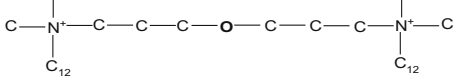 & -2.835 & -2.881 & -2.895 & -2.924 \\
\hline 7 & $\begin{array}{ccc}c-N^{+}-C-C-C-C-C-C-N^{+}-C \\
C_{12} & ! & C_{12}\end{array}$ & -2.884 & -2.890 & -2.884 & -2.923 \\
\hline 8 & 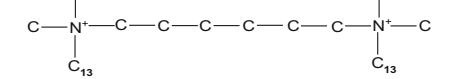 & -2.900 & -2.956 & -3.019 & -3.113 \\
\hline 9 & $\begin{array}{lr}i & i \\
i & 0-c \\
i & 0 \\
c_{9} & i \\
c_{9}\end{array}$ & -3.006 & -3.035 & -3.060 & -3.069 \\
\hline 10 & $\begin{array}{ll}i & ? \\
c_{9} & c_{9}\end{array}$ & -2.770 & -2.807 & -2.772 & -2.736 \\
\hline 11 & $\begin{array}{ll}\prod_{\mathrm{C}_{10}} & 0 \\
\mathrm{c}_{10}\end{array}$ & -2.900 & -2.956 & -2.946 & -2.940 \\
\hline 12 & 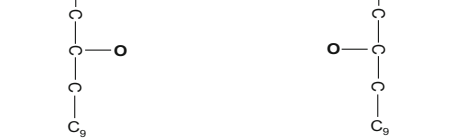 & -3.006 & -2.974 & -2.923 & -2.939 \\
\hline
\end{tabular}

${ }^{a}$ For this compound, the experimental values of $\mathrm{cmc}$ are $0.5(\mathrm{mM})$ at $20^{\circ} \mathrm{C}[23]$ and $2.2(\mathrm{mM})$ at about $23{ }^{\circ} \mathrm{C}[29]$ and the calculated values of $\mathrm{cmc}$ using models $1-4$ are about $1.9(\mathrm{mM})$ for $25^{\circ} \mathrm{C}$ 
Open Access This article is distributed under the terms of the Creative Commons Attribution 4.0 International License (http:// creativecommons.org/licenses/by/4.0/), which permits unrestricted use, distribution, and reproduction in any medium, provided you give appropriate credit to the original author(s) and the source, provide a link to the Creative Commons license, and indicate if changes were made.

\section{References}

1. Creton B, Nieto-Draghi C, Pannacci N (2012) Prediction of surfactants properties using multiscale molecular modeling tools: a review. Oil Gas Sci Tech 67:969-982. doi:10.2516/ogst/2012040

2. Yuan S, Cai Z, XuG JY (2002) Quantitative structure-property relationships of surfactants: prediction of the critical micelle concentration of nonionic surfactants. Colloid PolymSci 280:630-636. doi:10.1007/s00396-002-0659-2

3. Li X, Zhang G, Dong J, Zhou X, Yan X, Luo M (2004) Estimation of critical micelle concentration of anionic surfactants with QSPR approach. J MolStruct (THEOCHEM) 710:119-126. doi:10.1016/j. theochem.2004.08.039

4. Xu J, Zhu L, Fang D, Liu L, Wang L, Xu W (2013) Prediction of dielectric dissipation factors of polymers from cyclic dimmer structure using multiple linear regression and support vector machine. Colloid PolymSci 291:551-561. doi:10.1007/s00396-012-2743-6

5. Bortolotti M, Brugnara M, Della Volpe C, Maniglio D, Siboni S (2006) Molecular connectivity methods for the characterization of surface energetics of liquids and polymers. J Colloid Interface Sci 296:292-308. doi:10.1016/j.jcis.2005.09018

6. Wang Z-W, Feng J-L, Wang H-J, Cui Z-G (2005) Effectiveness of surface tension reduction by nonionic surfactants with quantitative structure-property relationship approach. J DispersSciTechnol 26: 441-447. doi:10.1081/DIS-200054572

7. Zhen L, Liu K, Huang D, Ren X, Li R (2016) Structure-property relationship of sulfosuccinic acid diester sodium salt micelles: 3DQSAR model and DPD simulation. J Dispersion SciTechol 37:941948. doi:10.1080/01932691.2015.1073601

8. Roy K, Kabir H (2012) QSPR with extended topochemical atom (ETA) indices: modeling of critical micelle concentration of nonionic surfactants. ChemEngSci 73:86-98. doi:10.1016/j. ces.2012.01.005

9. Roy K, Kabir H (2012) QSPR with extended topochemical atom (ETA) indices, 3: modeling of critical micelle concentration of cationic surfactants. ChemEngSci 81:169-178. doi:10.1016/j. ces.2012.07.008

10. Kier LB, Hall LH (1986) Molecular connectivity in structureactivity analysis. Research Studies Press Ltd, Letchworth

11. Mozrzymas A, Różycka-Roszak B (2011) Prediction of critical micelle concentration of cationic surfactants using connectivity indices. J Math Chem 49:276-289. doi:10.1007/s10910-010-9738-7

12. Mozrzymas A (2013) Modelling of the critical micelle concentration of cationic Gemini surfactants using molecular connectivity indices. J SolutChem 42:2187-2199. doi:10.1007/s10953-0130095-6

13. Mozrzymas A (2016) On the spacer group effect on critical micelle concentration of cationic gemini surfactants using molecular connectivity indices. Comb Chem High Throughput Screen 19: 481-488. doi:10.2174/1386207319666160504095717

14. Wang Z, Li G, Zang X, Wang R, Lou A (2002) A quantitative structure-propertyrelationship study for the prediction of critical micelle concentration of nonionic surfactants. Colloids Surfaces A: PhysEng Aspects 197:37-45. doi:10.1016/S0927-7757(01 )00812-3

15. Wiener H (1947) Structural determination of paraffin boiling points. J Am ChemSoc 69:17-20. doi:10.1021/ja01193a005

16. Randic M (1975) On characterization of molecular branching. J Am ChemSoc 97:6609-6615. doi:10.1021/ja00856a001

17. Wegrzyńska J, Chlebicki J, Maliszewska I (2007) Preparation, surface-active properties and antimicrobial activities of bis(ester quaternary ammonium) salts. J SurfactDeterg 10:109-116. doi:10.1007/s11743-007-1020-z

18. Han Y, Wang Y (2011) Aggregation behaviour of gemini surfactants and their interaction with macromolecules in aqueous solution. PhysChemChemPhys 13:1939-1956. doi:10.1039/c0cp01196g

19. Wegrzyńska J, Chlebicki J (2006) Preparation, surface-active properties and antielectrostatic properties of multiple quaternary ammonium salts. J SurfactDeterg 9:221-226. doi:10.1007/s11743-0065000-5

20. Quagliotto P, Viscardi G, Barolo C, Barni E, Bellinvia S, Fisicaro E, Compari C (2003) Geminipyridinium surfactants: synthesis and conductometric study of a novel class of amphiphiles. J Org Chem 68(20):7651-7660. doi:10.1021/jo034602n

21. Ding Z, Hao A (2010) Synthesis and surface properties of novel cationic gemini surfactants. J Dispersion SciTechol 31:338-342. doi:10.1080/019326909031922580

22. Contrera JF, MacLaughlin P, Hall LH, Kier LB (2005) QSAR modeling of carcinogenic risk using discriminant analysis and topological molecular descriptors. Current Drug Discovery Technol 2:55-67. doi:10.2174/1570163054064684

23. Kim T-S, Kida T, Nakatsuji Y, Hirao T, Ikeda I (1996) Surfaceactive properties of novel cationic surfactants with two alkyl chains and two ammonio groups. JAOCS 73:907-911. doi:10.1007/ BF02517994

24. Wettig SD, Li X, Verrall RE (2003) Thermodynamic and aggregation properties of gemini surfactants with ethoxylated spacers in aqueous solution. Langmuir 19:3666-3670. doi:10.1021/ la0340100

25. Wettig SD, Verrall RE (2001) Thermodynamic studies of aqueous m-s-mgemini surfactants systems. J Colloid Interface Sci 235:310 316. doi: $10.1006 /$ jcis 2000.7348

26. Akbar J, Tavakoli N, Marangoni DG, Wettig SD (2012) Mixed aggregate formation in gemini surfactant 1,2-dialkyl-sn-glycero-3phosphoethanolamine systems. J Colloid Interface Sci 377:237243. doi:10.1016/j.jcis.2012.03.048

27. $\mathrm{Hu}$ Z, Zhu H, Wang J, Cao D (2016) Surface activities of three anionic gemini surfactants derived from cyanuric chloride: effect of a branched hydrophobic chain. J SurfactDeterg 19:487-492. doi:10.1007/s11743-016-1812-0

28. Wettig SD, Nowak P, Verrall RE (2002) Thermodynamic and aggregation properties of gemini surfactants with hydroxyl substituted spacers in aqueous solution. Langmuir 18:5354-5359. doi:10.1021/ la011782s

29. Laschewsky A, Lunkenheimer K, Rakotoaly RH, Wattebled L (2005) Spacer effect in dimeric cationic surfactants. Colloid PolymSci 283:469-479. doi:10.1007/s00396-004-1219-8 